\title{
Research on the Influences of Resistivity for Steel Fiber Reinforced Concrete
}

\author{
Lin Longbin ${ }^{a}$, Lai Xiuying ${ }^{b}$ \\ Xiamen University Tan Kah Kee College, Fujian, Zhangzhou, PR of China, 363105 \\ allb@xujc.com, bxiuyinglai@xujc.com
}

\begin{abstract}
Keywords: Resistivity; Steel fiber reinforced concrete (SFRC); Orthogonal test
Abstract: In the subway engineering, increasing the resistivity of main structural material can improve the corrosion resistance to the stray current and the durability of structure. It is greatly significance to increase the resistivity of concrete by optimizing its mix proportion and realizing the influence of raw material on resistivity. Furthermore, it can also extend the service life of structure. This paper presents orthogonal experimental results from tests conducted on 9 groups of 27 specimens to evaluate the influence of three parameters such as steel fiber content, fly ash content and corrosion inhibitor content on the resistivity of steel fiber reinforced concrete (SFRC). Experimental results analyzed with range analysis and variance analysis indicate that fly ash content has a significant effect on the resistivity of SFRC, while both of steel fiber content and rust inhibitor content have not obvious. Analytical results provide an evidence for the application of SFRC in subway environment.
\end{abstract}

\section{Introduction}

In the last few years, several measurement methods used for concrete resistivity have been widely concerned by researchers. The resistivity value of concrete can be measured by using a simple test method, which can be taken as an indicator to evaluate the material performance and quality of concrete or the durability of concrete structure [1]. Several experimental studies have been conducted to investigate the resistivity of concrete [2,3,4]. These studies have shown that: (i) the measurement of resistivity can provide a basic reference for the durability evaluation of existing concrete structure, and (ii) the resistivity of SFRC is larger than that of reinforced concrete, and (iii) the stray current corrosion resistance of SFRC is better than that of reinforced concrete.

In the subway operating environment, the rebar is prone to be corroded due to the existing of stray current, which will affect the durability of main structure and shorten its service life [2]. The corrosion of steel fiber and rebar caused by stray current reduces when the resistance value of SFRC increases, therefore the durability of main structure is better. It is exceedingly significant to extend the service life of concrete structure, which will come true by improving the resistivity of SFRC with an appropriate design of concrete mix proportion. In this paper, orthogonal experiments on the influence of steel fiber content (SF), fly ash content (FA) and corrosion inhibitor content (CI) on the resistivity of SFRC was carried out. Both the variance analysis and range analysis are used to analyze the results. Analytical results provide an evidence for the application of SFRC in subway environment.

\section{Design of Orthogonal Experiment}

Parameters. The method of orthogonal experiment can fully reflect the inherent law of test by as little test number as possible and consider as more the factors as possible at the same time. It's a scientific method to found out the optimum levels and main factors [6]. Therefore, this method is adopted in this experiment. A total of 9 groups (27 specimens, as shown in Figure 1) with three parameters such as steel fiber content (A-SF), fly ash (B-FA) content and rust inhibitor (C-CI) content are designed to investigate the influence of resistivity for SFRC. All the three parameters are divided into 3 levels (as shown in Table 2) with percentage by weight.

Table 1 summarizes the factors, levels and experimental results for orthogonal experiment. 
Table $1 \mathrm{~L} 9\left(3^{4}\right)$ The orthogonal experiment design and result

\begin{tabular}{llllllll}
\hline \multirow{2}{*}{ Specimens } & \multicolumn{2}{l}{ A-SF [\%] } & \multicolumn{3}{c}{ B-FA [\%] } & C-CI [\%] & Resistivity \\
\cline { 2 - 7 } & Column & Levels & Column & Levels & Column & Levels & {$[\Omega \cdot \mathrm{m}]$} \\
\hline 1 & 1 & $0.50 \%$ & 1 & $0 \%$ & 3 & $4 \%$ & 220 \\
\hline 2 & 2 & $1 \%$ & 1 & $0 \%$ & 1 & $0 \%$ & 253.3 \\
\hline 3 & 3 & $1.50 \%$ & 1 & $0 \%$ & 2 & $2 \%$ & 305 \\
\hline 4 & 1 & $0.50 \%$ & 2 & $15 \%$ & 2 & $2 \%$ & 410.8 \\
\hline 5 & 2 & $1 \%$ & 2 & $15 \%$ & 3 & $4 \%$ & 441.7 \\
\hline 6 & 3 & $1.50 \%$ & 2 & $15 \%$ & 1 & $0 \%$ & 436.7 \\
\hline 7 & 1 & $0.50 \%$ & 3 & $30 \%$ & 1 & $0 \%$ & 569.2 \\
\hline 8 & 2 & $1 \%$ & 3 & $30 \%$ & 2 & $2 \%$ & 513.3 \\
\hline 9 & 3 & $1.50 \%$ & 3 & $30 \%$ & 3 & $4 \%$ & 668.3 \\
\hline
\end{tabular}

Figure 1 Specimens of SFRC

Mix Proportion. The concrete grade is $\mathrm{C} 40$ with the water-cement ratio of 0.41 . Table 2 summarizes all the mix proportions of SFRC.

Table 2 All the mix proportions of SFRC

\begin{tabular}{llllllllll}
\hline Specimens & $\begin{array}{l}\text { Steel } \\
\text { fiber } \\
{[\mathrm{kg}]}\end{array}$ & $\begin{array}{l}\text { Water } \\
{[\mathrm{kg}]}\end{array}$ & $\begin{array}{l}\text { Cement } \\
{[\mathrm{kg}]}\end{array}$ & $\begin{array}{l}\text { Fly } \\
\text { ash } \\
{[\mathrm{kg}]}\end{array}$ & $\begin{array}{l}\text { Sand } \\
{[\mathrm{kg}]}\end{array}$ & $\begin{array}{l}\text { Coarse } \\
\text { Aggregate } \\
{[\mathrm{kg}]}\end{array}$ & $\begin{array}{l}\text { Water } \\
\text { reducer } \\
{[\mathrm{kg}]}\end{array}$ & $\begin{array}{l}\text { Corrosion } \\
\text { inhibitor } \\
{[\%]}\end{array}$ & $\begin{array}{l}\text { Slump } \\
{[\mathrm{cm}]}\end{array}$ \\
\hline 1 & 39.25 & 166 & 405 & 0 & 717 & 1075 & 7.29 & 16.2 & 18 \\
\hline 2 & 78.5 & 168 & 410 & 0 & 750 & 1035 & 8.2 & 0 & 9 \\
\hline 3 & 117.75 & 170 & 415 & 0 & 781 & 995 & 9.13 & 8.3 & 12.5 \\
\hline 4 & 39.25 & 166 & 344 & 61 & 717 & 1075 & 8.1 & 8.1 & 10 \\
\hline 5 & 78.5 & 168 & 349 & 61 & 750 & 1035 & 8.61 & 16.4 & 17 \\
\hline 6 & 117.75 & 170 & 353 & 62 & 781 & 995 & 9.96 & 0 & 16 \\
\hline 7 & 39.25 & 166 & 284 & 122 & 717 & 1075 & 8.12 & 0 & 13 \\
\hline 8 & 78.5 & 168 & 287 & 123 & 750 & 1035 & 8.61 & 8.2 & 19 \\
\hline 9 & 117.75 & 170 & 291 & 125 & 781 & 995 & 10.83 & 16.64 & 17 \\
\hline
\end{tabular}

Note: Size of specimen is $100 \mathrm{~mm} \times 100 \mathrm{~mm} \times 100 \mathrm{~mm}$, as shown in Fig. 1.

Testing Principle. The resistivity of SFRC specimens was measured with the condition of curing period of $28 \mathrm{~d}$ and moisture content of $100 \%$. The method of two electrodes is used to measure the resistivity in this test, as shown in Figure 2. Two parallel electrodes are set on both sides of specimen. The resistance value between the two electrodes is measured by multimeter (type MT-2017), which is a traditional analogue type and produced by Baogong Co.Ltd in Taiwan, China. The resistivity of concrete can be calculated from the formula shown as the following [4].

$$
\rho=R \frac{A}{L}
$$

Where $\rho$ is resistivity in $\Omega \bullet \mathrm{m}, A$ is cross-sectional area in $\mathrm{m}^{2}$, all the cross-sectional area of the specimens are $0.01 \mathrm{~m}^{2}, R$ is resistance in $\Omega, L$ is length of specimen in $\mathrm{m}$. 

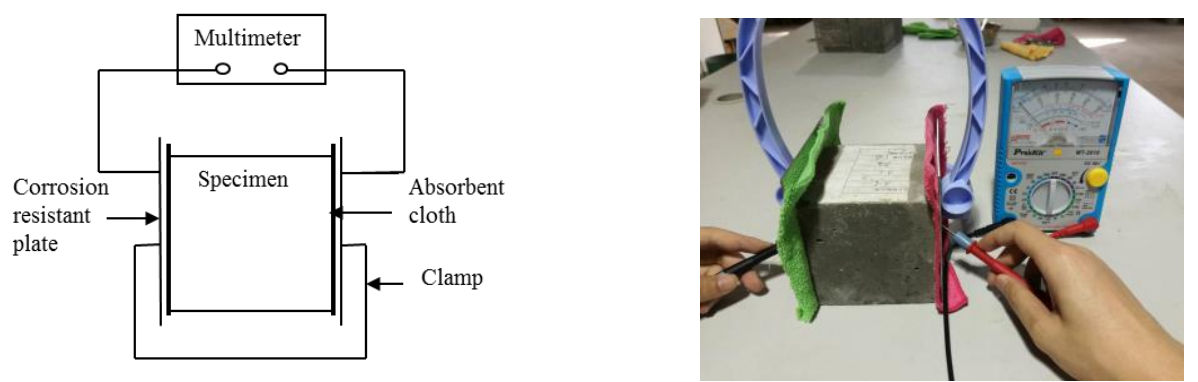

Figure 2 The measure principle of resistivity for method of two electrodes

\section{Result Analysis}

The range analysis method is simple and easy to be understood. The major-minor order of test factors and best combination of best factors can easily be obtained by simple calculation and indicators. However, the test results have been influenced by test errors, factors and some interaction between factors. But the range analysis can't estimate the error bound which exists in the test and test data. The errors can't be analyzed. In order to evaluate the influence of the three parameters on resistivity more objectively, both the range analysis method and variance analysis method are used to discuss the test result in this paper. Both the analyzed results calculated by the two methods indicated that the content of FA significantly affect the resistivity of SFRC, while the influence of the other two parameters are not obvious (as shown in Table 3 and Table 4). Compared to range analysis, the results of variance analysis are quantitative with a quantity of $90 \%$, as shown in table 4 noted by $(*)$.

Table 3 The orthogonal experiment result with range analysis method

\begin{tabular}{lllll}
\hline Indicator & Parameters & A-SF & B-FA & C-CI \\
\hline \multirow{4}{*}{$\begin{array}{l}\text { Resistivity } \\
(\Omega \cdot \mathrm{m})\end{array}$} & $K_{1}$ & 1200.0 & 778.3 & 1259.2 \\
\cline { 2 - 5 } & $K_{2}$ & 1208.3 & 1289.2 & 1229.1 \\
\cline { 2 - 5 } & $K_{3}$ & 1410.0 & 1750.8 & 1330.0 \\
\cline { 2 - 5 } & $k_{1}$ & 400.0 & 259.4 & 419.7 \\
\cline { 2 - 5 } & $k_{2}$ & 402.8 & 429.7 & 409.7 \\
\cline { 2 - 5 } & $k_{3}$ & 470.0 & 583.6 & 443.3 \\
\cline { 2 - 5 } & Range $(R)$ & 70.0 & 324.2 & 33.6 \\
\hline
\end{tabular}

Table 4 The orthogonal experiment results with variance analysis method

\begin{tabular}{llllll}
\hline $\begin{array}{l}\text { Sources } \\
\text { variation }\end{array}$ & of Sum-of-squares & $\begin{array}{l}\text { Degrees of } \\
\text { freedom }\end{array}$ & $\begin{array}{l}\text { Mean } \\
\text { sum } \\
\text { square }\end{array}$ & $\begin{array}{l}\text { The } \\
\text { value } \\
\text { of Fi }\end{array}$ & $\begin{array}{l}\text { Significant } \\
\text { level } \alpha\end{array}$ \\
\hline A-SF & 9428.0 & 2 & 4714.0 & 1.8 & No effect \\
\hline B-FA & 157761.0 & 2 & 78880.5 & $29.6^{(*)}$ & $\begin{array}{l}0.05 \text { significant } \\
\text { effect }\end{array}$ \\
\hline C-CI & 1788.8 & 2 & 894.4 & 0.3 & No effect \\
\hline Error & 5325.9 & 2 & 2662.9 & $/$ & $/$ \\
\hline Summation & 174303.7 & 8 & $/$ & $/$ & $/$ \\
\hline Note: $F_{0.01}(2,2)=99$, & $F_{0.05}(2,2)=19$, & $F_{0.1}(2,2)=9$, & $F_{0.25}(2,2)=3$
\end{tabular}

\section{Parameter Analysis}

The relative magnitudes of the different parameters are discussed by Range analysis. Furthermore, the results were tested for significance by variance analysis. The variation tendency of resistivity affected by the three parameters is showed in Figure 3.

From Figure 3, it shows that that the resistivity of SFRC has a positive relationship with the content of FA. The resistivity increases with the increasing of content of FA. The filling effect of FA improves the internal microstructure of SFRC and smaller its pore structure. Therefore, the 
resistivity of SFRC improves with the increasing of FA by reducing the content of calcium hydroxide in SFRC. The same results have been carried out by Liu \& Zan [7] and Hussain [8]. Due to the disordered distribution of steel fiber, the conductivity of SFRC rarely improves compared to normal concrete [9]. Therefore, the variation of steel fiber content has not obviously affected the resistivity of SFRC. The content of corrosion inhibitor adding in the test is lower and its influence on resistivity of SFRC is also not obvious.

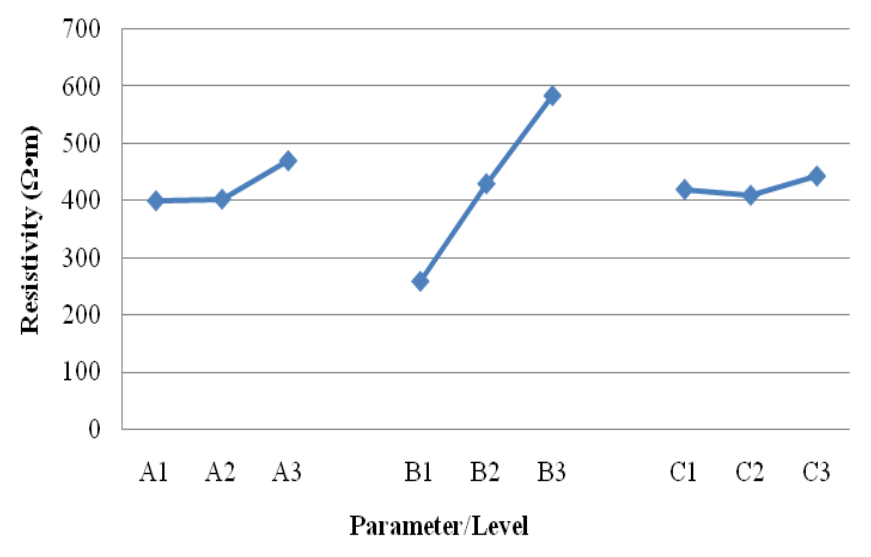

Figure.3 The influence of the three parameters on resistivity of SFRC

\section{Summary}

This paper presents orthogonal experimental results from tests conducted on 9 groups of 27 specimens to evaluate the influence of three parameters such as steel fiber content, fly ash content and corrosion inhibitor content on the resistivity of SFRC. Experimental results analyzed with range analysis and variance analysis indicate that: (i) the resistivity of SFRC increases with the increasing of content of fly ash, it can increase the resistivity of SFRC by increasing the content of fly ash in the application of subway engineering, therefore the durability of structure can be better; (ii) both of steel fiber content and rust inhibitor content have not obvious.

In this paper, only the three parameters are discussed. More researches such as the influence of external parameters need to be carried out in future.

\section{Acknowledgements}

This work was financially supported by Fujian Province young and middle-aged teacher education project (JA15613).

\section{References}

[1] Q. Jueshi, X. Shanshan, L. Meili and W. Lixia: The Measurement and Application of Resistivity for Concrete. Journal of Shandong University of Science and Technology, Vol. 29 (2010), p. 37

[2] S. Nannan, Z. Qiang and D. Xiaoqian: An experimental study of the influence of sodium chloride on the strength of cement mortar using electrical resistivity method. China Science paper, Vol. 10 ( 2015), p. 1563

[3] Z. Zhuo, Z. Li and W. Dong-wei: Correlation Test of Correlation between Concrete Resistivity and Chloride Diffusion Coefficient. Journal of Zhengzhou University (Engineering Science), Vol. 34 (2013), p. 76

[4] G. Li-ping, D. Cong, Y. Bo and S. Bin. Electrical resistivity of steel fiber reinforced concrete and reinforced concrete. Journal of Hebei University of Technology, Vol. 43 (2014), p. 26

[5] L. Longbin. Experimental study on stray current corrosion to reinforced concrete and steel fiber reinforced concrete. Fujian Architecture \& Construction, Vol. 136 (2009), p. 115 
[6] J. Tongchuan: Orthogonal Test, Jinan: Shandong Technology Press (1985).

[7] L. Zhiyong and Z. Zhenfeng: Research on electrical resistivity of concrete and its application in durability appreciation of reinforced concrete. Concrete, Vol. 204 (2006), p. 13

[8] Hussain SE, Rasheeduzzafar: Corrosion Resistance Performance of Fly Ash Blended Cement Concrete. Aci Materials Journal, Vol. 91 (1994), p. 264

[9] H. Lei and H. Yuanyuan: Effect of the rust inhibitor on the conductive properties of SIFCON. Concrete, Vol.220 (2008), p.79 